\title{
CERVICAL MENINGOCELE IN A NEWBORN: A CASE REPORT
}

\author{
Eylül Şenödeyici ${ }^{1}$, Ahmet Tolgay Akınc1², Yener Aktürk ${ }^{2}$ \\ ${ }^{1}$ Trakya University School of Medicine, Edirne, TURKEY \\ ${ }^{2}$ Department of Neurosurgery, Trakya University School of Medicine, Edirne, TURKEY
}

\begin{abstract}
Aims: Neural tube defects are among the most common congenital anomalies worldwide, with a wide range of subtypes. The aim of this case report is to present a patient with cervical meningocele, a rare type of neural tube defect. Case Report: A 33-year-old pregnant woman with a story of bearing an anencephalic baby was referred to Trakya University Hospital with a probable cystic hygroma diagnosis on the 31st week of pregnancy. An antenatal ultrasound revealed a protrusion on the posterior cervical region. Two days before the planned delivery, fetal magnetic resonance imaging was performed by the decision of the council. The 61 x 37 millimeters cyst was planned to be removed upon birth. On the 38th week, the baby was delivered by cesarean section with no other complications. After a preoperative magnetic resonance imaging, surgical procedure including the excision of the cyst and the duroplasty was performed. Conclusion: A rare and devastating congenital anomaly, cervical meningocele, requires accurate diagnosis and prompt surgical involvement for effective treatment and good prognosis. Keywords: Meningocele, cervical meningocele, neurosurgery, neural tube defects
\end{abstract}

\section{INTRODUCTION}

Neural tube defects (NTDs) are congenital anomalies affecting the central nervous system, and originating during embryonic development by incomplete closure of the neural tube (1). NTDs are divided into two groups, spina bifida occulta and spina bifida aperta. Spina bifida occulta can be defined as the neural defect being "closed" by ectoderm, thus preventing cerebrospinal fluid leakage. In a case of spina bifida aperta, however, there is no full coverage by ectoderm. This leaves the neural defect "open", and causes cerebrospinal fluid leakage (2).

NTDs are among the most common congenital anomalies worldwide, occurring at a range of 0.5-10 per 1000 live births, with a geographic variation of incidence $(1,3)$. The risk for the next pregnancy for couples that had an offspring with an NTD has been reported to be 40 per 1000 live births (4). Meningocele is a type of spina bifida occulta, which appears as a protrusion of the meninges filled with cerebrospinal fluid, often in the lumbosacral region and without being accompa- nied by neural tissue (5). Thus, neurologic deficits are generally not expected (6). However, the spinal cord may still be tethered, eventually causing symptoms (7). Meningocele cases that affect the cervical region are less frequent, accounting for 1-5\% of all NTDs (8). Children with cervical meningoceles should be observed strictly as this particular type of meningocele may be associated with other spinal abnormalities (9). Although the exact cause of this defect is not known, low levels of maternal folate during the early stages of pregnancy, diabetes, and obesity are believed to be involved $(1,10)$.

\section{CASE REPORT}

A pregnant woman was directed to Trakya University Hospital on the $31^{\text {st }}$ week of pregnancy with a suspected cystic hygroma on the baby. After undergoing an antenatal ultrasound, the baby was diagnosed with a cervical meningocele. The mother was 33 years of age, who had a story of labour arrest in her first pregnancy and bearing an anencephalic baby on her second.

Address for Correspondence: Eylül Şenödeyici, Trakya University School of Medicine, Edirne, TURKEY 
She regularly used medication for asthma during this pregnancy. Two days before the planned delivery, she was admitted to the obstetrics service in our hospital. The council decided for an evaluation from the departments of neurosurgery and pediatric surgery, along with fetal MRI. Fetal MRI confirmed that an exophytic cyst of $61 \times 37$ millimeters covered by a thin layer of skin on the posterior cervical region was present, contiguous with the vertebral column, and contained some septation (Figure 1-3). The right renal pelvis was more prominent than the left. No other abnormalities were detected.

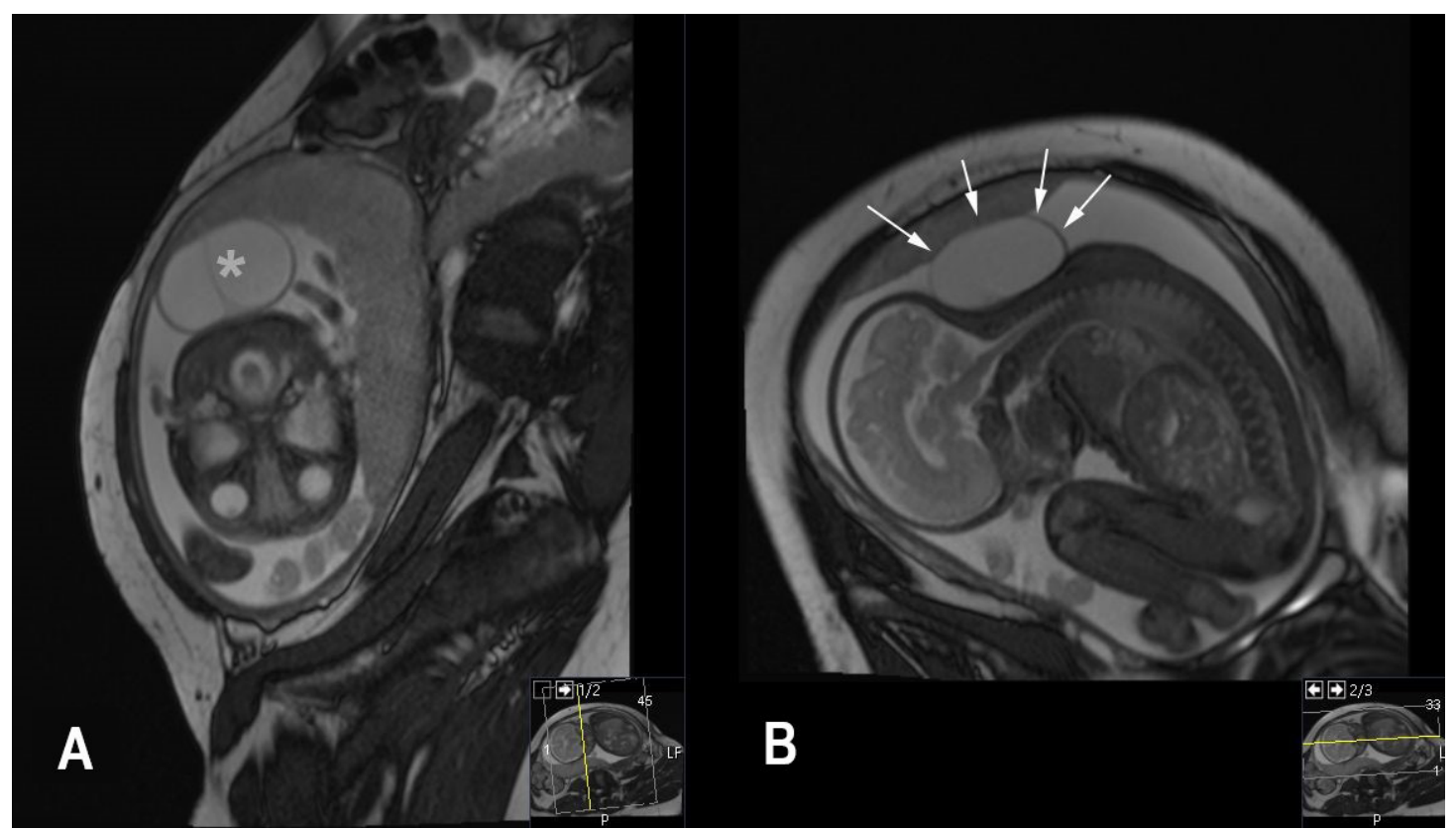

Figure 1: Fetal MRI. A: T2-weighted images, axial sections, The meningocele sac (Asterix). B: T2-weighted images, sagittal sections, The borders of the meningocele sac (Arrow).

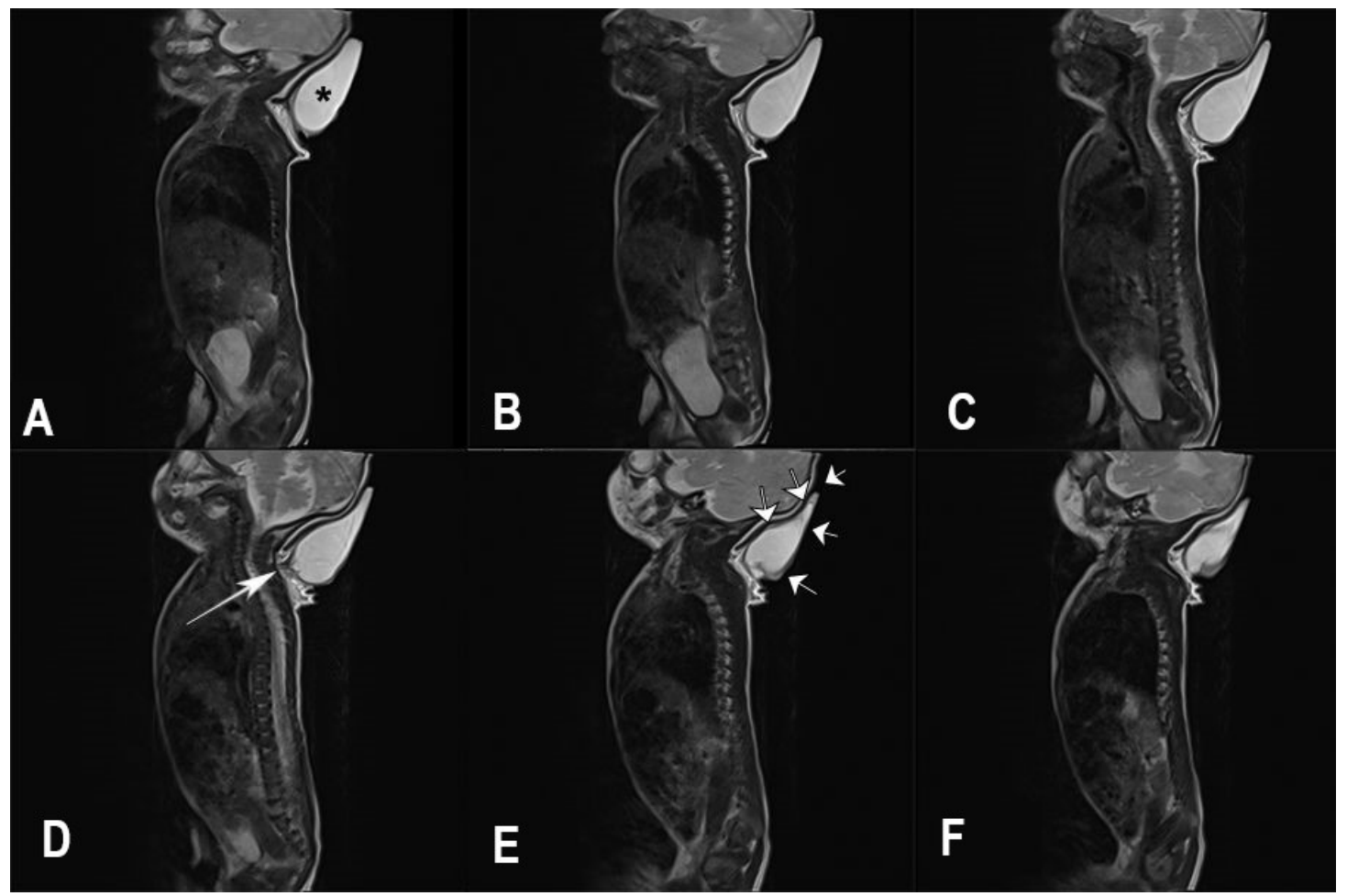

Figure 2: Neonatal MRI. A-F: T2-weighted images, sagittal sections. A: The meningocele sac (Asterix). D: The connection to the spinal canal (Arrow). E: Skin covering the meningocele sac (Arrows). 


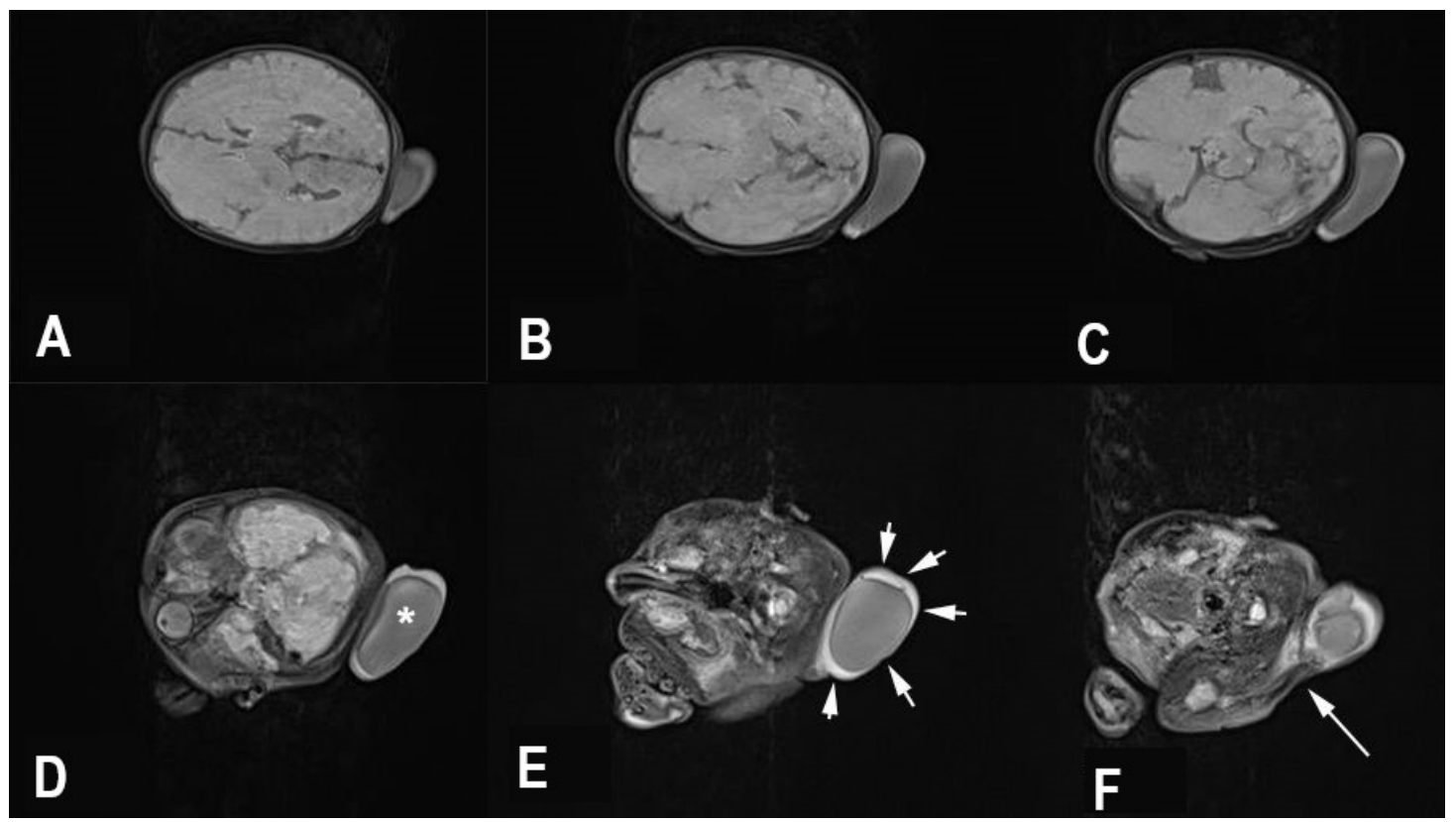

Figure 3: Neonatal MRI. A-F: T2-weighted images, axial sections. D: The meningocele sac (Asterix). E: Skin covering the meningocele sac (Arrows). F: The connection to the spinal canal (Arrow).
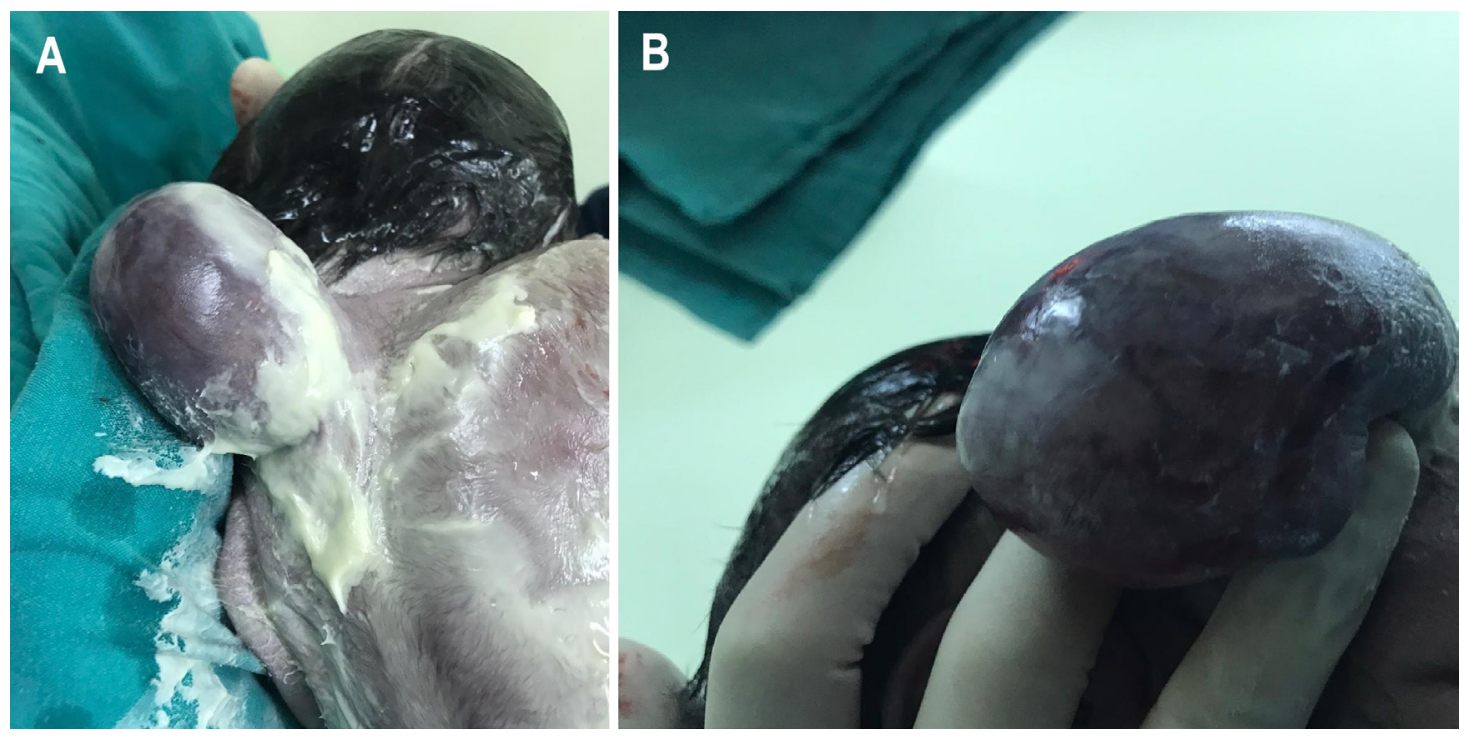

Figure 4: A,B: Preoperative pictures of the meningocele sac.

The baby was delivered by cesarean section, weighing 3.14 kilograms. The next day, he was taken to the operating room to have the cyst removed. Preoperative images of the cyst were given in Figure 4.

The infant was placed in a prone position. The cyst was opened with a ring-shaped incision and dissected by using dissecting scissors and cautery (Figure 5A). The dural layer and its borders were inspected, and a ring-shaped maneuver around it was made to remove the cyst (Figure 5B). Later, the paravertebral muscles were retracted to reach and cover the pathologic opening at the 7 th cervical vertebra level (Figure 5C). Neural roots and the associated structures were collected inside (Figure 5D), and then dural layer was closed in a waterproof fashion, using 5-0 sutures (Figure 5E). Fibrin glue was applied. After meticulous hemostasis, the remaining layers were closed (Figure 5F).

There were not any complications in the postoperative follow-up. The patient was also examined after 6 months and no neurological deficits were detected. 


\section{(PTMSI}
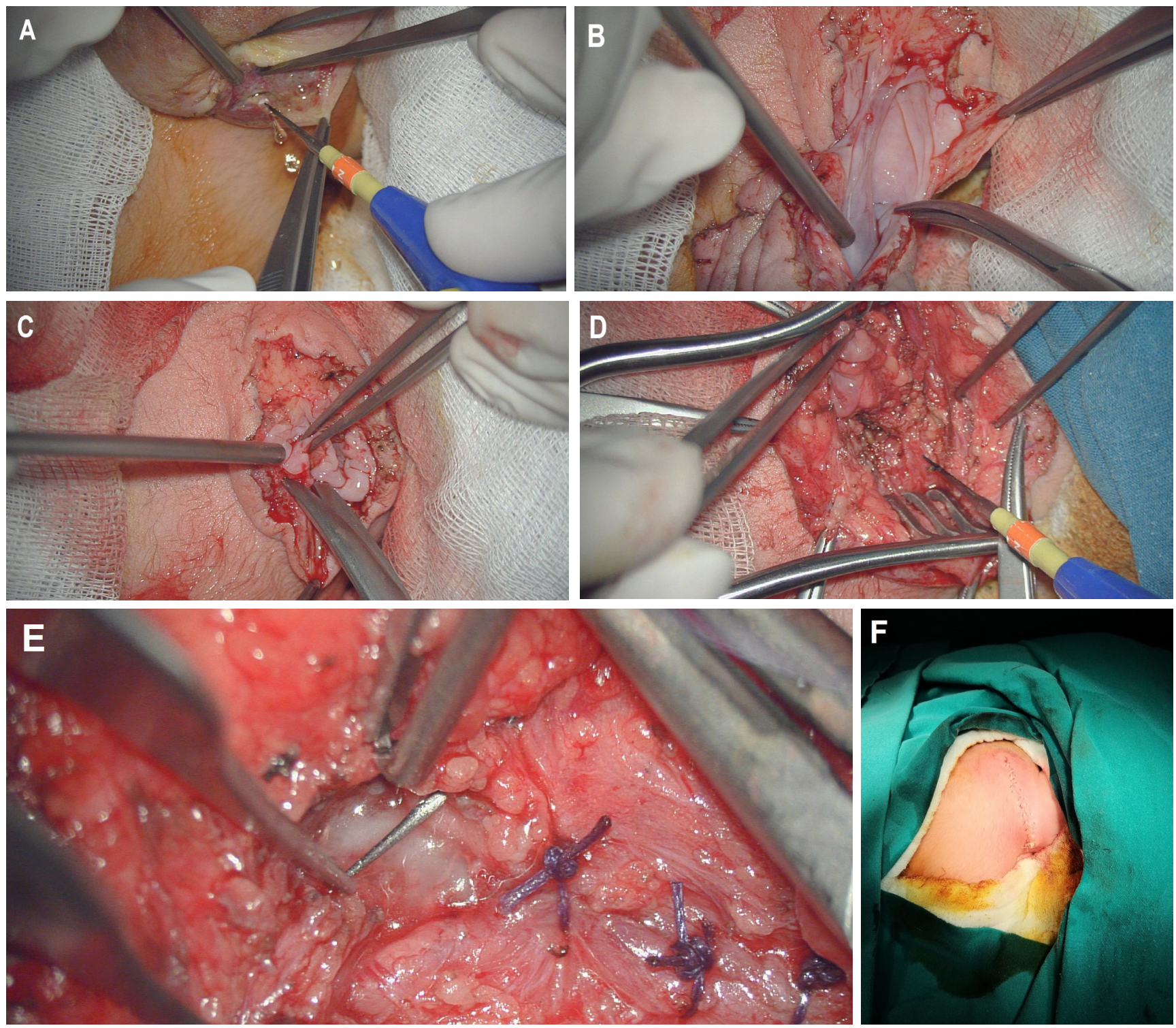

Figure 5: A-F: Pictures of the operation phases.

\section{DISCUSSION}

Spinal dysraphism is divided into two distinct categories. When planning a surgical involvement for such cases, the type of the lesion must be taken into consideration. In a case of spina bifida aperta, the neural canal is open, and the absence of a layer covering the neural tissue increases the risk of life-threatening complications such as infection and excessive loss of cerebrospinal fluid. These cysts should be removed as early as possible after birth (11). For spina bifida occulta cases, however, surgical procedure should be completed within 72 hours from birth and an MRI of the whole spinal column is recommended (12).

With proper surgical involvement, the prognosis for the newborn with cervical meningoceles is generally excellent (13). However, lesions should still be evaluated with care, as there may be underlying conditions such as hydrocephalus, syringomyelia, diastematomyelia, and tethered cord with progressive neurological deteriorations in the limbs $(8,13)$.

The removal of the lesion should be performed within the aforementioned time intervals, for early treatment is highly essential to prevent infection, sac injury and additional neurological defects that may occur in the future $(13,14)$. Erşahin et al. (13) reported that once the symptoms of tethered cord have developed, especially in the case of sphincter dysfunction, surgical involvement is unlikely to reverse the outcome. In another study conducted by Öncel et al. (14) the association between early surgical involvement and a shortened duration of hospital stay was highlighted. It was also 
stated that early surgical involvement increases the likelihood of a maintained function of the urinary tract (14).

In our case, the surgical procedure was completed within the first 24 hours from birth. This will highly decrease the risk of aforementioned future anomalies, while. significantly improving the patient's overall health in the following years. It was made sure that no tethering was present by investigating the pathologic area at the seventh vertebra level. On the 6 months follow-up of our case, no neurological deficits were detected.

Konya et al. (15) presented a 47-year-old patient whose cervical meningocele was not treated upon birth and manifested symptoms in adulthood, such as fluid leakage from the sac which was infected, walking difficulty, stiffness in lower extremities and tethered cord syndrome. Although there was no recurrence in symptoms 12 months after surgery involving the excision of the cyst, it was noted that untreated tethered cord might pose a severe risk and careful assessment for possible tethering pathologies is vital (15).

In conclusion, regardless of the lesion's nature, a multidisciplinary approach involving the departments of pediatry, radiology, obstetrics and neurosurgery is needed for an effective treatment of cervical meningoceles. Post-surgical follow-ups are highly important to maintain a good prognosis in the long term. As in the rest of spinal dysraphism, early detection and prompt surgical involvement significantly improve the prognosis of cervical meningoceles.

\section{Ethics Committee Approval: N/A}

Informed Consent: Written informed consent was obtained from the patient's family.

Conflict of Interest: The authors declared no conflict of interest.

Author contributions: Concept: EŞ, ATA, YA Supervision: EŞ, ATA, YA Resources: EŞ,ATA, YA Materials: EŞ, ATA, YA Data collection and/or processing: EŞ, ATA, YA Analysis and/or Interpretation: BEŞ, ATA, YA Literature Search: EŞ, ATA, YA Writing Manuscript: EŞ, ATA, YA Critical Review: EŞ, ATA, YA

Financial disclosure: The authors declared that this study received no financial support.

\section{REFERENCES}

1. Greene ND, Copp AJ. Neural tube defects. Annu Rev Neurosci 2014;37:221-42.

2. Lemire RJ. Neural tube defects. JAMA. 1988 Jan 22-29;259(4):558-

62.

3. Hynd GW, Morgan AE, Vaughn M. Neurodevelopmental malfor- mations: etiology and clinical manifestations. In: Reynolds CR, Fletcher-Janzen E, editors. Handbook of clinical child neuropsychology. 3rd ed. New-York: Springer; 2009.p.147-68.

4. Nussbaum RL, McInnes RR, Willard HF. Risk assessment and genetic counseling. In: thompson \& thompson genetics in medicine. 8th ed. Philadelphia: Elsevier; 2016.p.333-48.

5. Gupta N, Ross ME. Disorders of neural tube development. In: Swaiman KF, Ashwal S, Ferriero DM et al. Swaimans pediatric neurology: principles and practice. Edinburgh: Elsevier; 2018.p.437-58.

6. Sun JCL, Steinbok P, Cochrane DD. Cervical myelocystoceles and meningoceles: long-term follow-up. Pediatric Neurosurgery 2000;33(3):118-22.

7. Huang SB, Dohery D, Congenital malformations of the central nervous system. In: Gleason CA, Juul SE, editors. Averys diseases of the newborn. Philadelphia, PA: Elsevier; 2018.p.877

8. Denaro L, Padoan A, Manara R et al. Cervical myelomeningocele in adulthood. Neurosurgery 2008;62(5)1169-71.

9. Delashaw JB, Park TS, Cail WM et al. (1987). Cervical meningocele and associated spinal anomalies. Child's Nervous System 1987;3(3):165-9.

10. Salih MA, Murshid WR, Seidahmed MZ. Epidemiology, prenatal management, and prevention of neural tube defects. Saudi Med J. 2014 Dec;35 Suppl 1(Suppl 1):S15-28.

11. Sahni M, Ohri A. Meningomyelocele. In: StatPearls. Treasure Island (FL): StatPearls Publishing; 2020. Available from: URL: https:// www.ncbi.nlm.nih.gov/books/NBK536959/.

12. Erşahin Y, Barçin E, Mutluer S. Is meningocele really an isolated lesion. Child's Nerv Syst 2001;17(8):487-90.

13. Levene MI, Chervenak FA. Surgical management of neural tube defects. In: Fetal and neonatal neurology and neurosurgery. 4th ed. Churchill Livingstone; 2008.p.851

14. Öncel MY, Özdemir R, Kahilogulları G et al. The effect of surgery time on prognosis in newborns with meningomyelocele. J Korean Neurosurg Soc 2012;51(6):359-62.

15. Konya D, Dagcinar A, Akakin A et al. Cervical meningocele causing symptoms in adulthood. Journal of Spinal Disorders \& Techniques. 2006;19(7):531-3. 